Article

\title{
Induration Process of MgO Flux Pellet
}

\author{
Qiangjian Gao*, Xin Jiang *, Haiyan Zheng and Fengman Shen \\ School of Metallurgy, Northeastern University, Shenyang 110819, China; zhenghy@smm.neu.edu.cn (H.Z.); \\ shenfm@mail.neu.edu.cn (F.S.) \\ * Correspondence: gaoqiangjian@163.com or gaoqj@smm.neu.edu.cn (Q.G); jiangx@smm.neu.edu.cn (X.J.); \\ Tel.: +86-24-8368-1506 (Q.G. \& X.J.)
}

Received: 16 July 2018; Accepted: 4 September 2018; Published: 5 September 2018

\begin{abstract}
The induration process of oxidized pellet, containing the oxidation of magnetite phase $\left(\mathrm{Fe}_{3} \mathrm{O}_{4}\right)$ and the sintering of oxidized magnetite phase (hematite- $\left.\mathrm{Fe}_{2} \mathrm{O}_{3}\right)$, is significant to obtain sufficient pellet strength. The current study focuses on the induration mechanisms of $\mathrm{MgO}$ flux pellet in terms of the oxidation process of $\mathrm{Fe}_{3} \mathrm{O}_{4}$ and densification process of the pellet. It is found that $\mathrm{MgO}$ dosage negatively affects the oxidation of $\mathrm{Fe}_{3} \mathrm{O}_{4}$ into $\mathrm{Fe}_{2} \mathrm{O}_{3}$. The number of recrystallized grain of $\mathrm{Fe}_{2} \mathrm{O}_{3}$ in the $\mathrm{MgO}$ flux pellet is less than that in the Non-MgO flux pellet. Additionally, an unreacted core model was applied to consider and clarify the oxidation of $\mathrm{Fe}_{3} \mathrm{O}_{4}$. According to the verification experiments, the experimental data and calculated results fit well. Therefore, the unreacted core model can describe the oxidation of $\mathrm{Fe}_{3} \mathrm{O}_{4}$ in the pellet induration process. Moreover, based on the development of pore parameters during the pellet induration process, a new index, the so-called oxide densification index (ODI) was defined to profoundly specify the densification degree of the pellet. The results show that the ODI of the $\mathrm{MgO}$ flux pellet maintains at a lower level compared with that of the Non-MgO flux pellet. It illustrates that $\mathrm{MgO}$ can substantially restrain the pellet densification process.
\end{abstract}

Keywords: pellet; $\mathrm{MgO}$; induration; unreacted core model; oxide densification index (ODI)

\section{Introduction}

Agglomeration of iron ore pellet begins with the grinding and cleaning of the iron ore to meet the desired chemical quality. The pelletizing is done in a large pelletizing disc using water together with an external binder as a binding medium. The wet green pellet is then dried and sintered in the pelletizing machine to obtain fired pellet [1]. Acid pellet, as a traditional iron bearing burden for blast furnace (BF), has many merits in terms of metallurgical properties and intrinsic properties [2]. For instance, the mechanical strength of acid pellet is better, which is favorable for a pellet to withstand double forces in $\mathrm{BF}$ process including the extrusion force from the top layer burden and the friction force from the high-speed gas flow beneath the furnace; the iron-grade of pellet is higher, which is favorable for effective iron content input in burden column and enhancing production efficiency; the particle size of pellet is relatively uniform, favorable for burden permeability of BFs. Therefore, the pellet portion in burden materials is increasing (20\% in China and even $100 \%$ in some BFs of Europe and North America [3]).

However, a traditional acid pellet also has some inevitable drawbacks. When the acid pellet is reduced in $\mathrm{BF}$, the lower melting point mineral (fayalite) gradually appears due to the higher reaction rate between $\mathrm{FeO}$ and $\mathrm{SiO}_{2}$ [4]. As a result, the softening and melting behavior of the pellet is a challenging issue, which may lead to lower permeability of cohesive zone [5]. In addition, the reduction swelling index (RSI) of acid pellet is even up to $30 \%$ in some ironmaking plants. Thus, the reduction swelling of the acid pellet is the other limit for its utilization in the BF process. For the purpose of 
overcoming the drawbacks of acid pellets, it is possible to introduce fluxes into the pellet. For example, a $\mathrm{CaO}$-bearing flux can be added to produce a $\mathrm{CaO}$ flux pellet for improvement in the softening and melting properties. Nevertheless, the reduction swelling is still evident and results in a $\mathrm{CaO}$ flux pellet that cannot be used in BFs on a large scale [6]. MgO flux pellet was recently developed as an alternative candidate for the following reasons summarized from some previous studies $[4,7,8]:(1)$ $\mathrm{MgO}$ flux pellet can respectively improve the softening and melting properties, reduction swelling index (RSI), and reduction disintegration index (RDI); (2) $\mathrm{MgO}$ flux pellet can meet the $\mathrm{MgO}$ needs in slagging process of a $\mathrm{BF}$, which makes it possible to fulfill the reasonable cohesive zone configuration, the favorable gas distribution in BF, as well as the better metallurgical properties of BF slag.

Besides, some research and practices have also indicated that $\mathrm{MgO}$ can weaken pellet strength. In a previous paper [9], it is pointed out that $\mathrm{MgO}$ adversely affects pellet strength due to the solid solution between the $\mathrm{MgO}$ and $\mathrm{FeO}$. Ahmed et al. [10] claimed that $\mathrm{MgO}$ in olivine can start to significantly react with $\mathrm{Fe}_{3} \mathrm{O}_{4}$ after $1000{ }^{\circ} \mathrm{C}$, and at $1250{ }^{\circ} \mathrm{C}$ fine olivine particles react completely whereas the reaction is limited for larger olivine particles. Also, the practice results in Baotou Iron and Steel Corporation China (Baotou, Inner Mongolia province, China) has shown that [11] when $\mathrm{MgO}$ content in pellet increases from $0 \%$ to $2.0 \%$, the compressive strength decreases by about $500 \mathrm{~N} /$ pellet. Semberg et al. [12] also maintained that $\mathrm{MgO}$ addition obviously restrains the pellet strength, especially by using a fine olivine $(<38 \mu \mathrm{m})$. Singh et al. [13] stated that conversion from magnetite $\left(\mathrm{Fe}_{3} \mathrm{O}_{4}\right)$ to hematite $\left(\mathrm{Fe}_{2} \mathrm{O}_{3}\right)$ is a key for sinter or pellet obtaining better strength, $\mathrm{MgO}$ substantially participates in the conversion process. Similarly, targeting to obtain desired pellet strength, the MgO dosage in pellet for Shougang Jingtang Iron and Steel Corporation China (Tangshan, Hebei province, China) is controlled at a level of no more than $2.0 \%$ [14].

On the basis of the analysis mentioned above, we can summarize that a proper $\mathrm{MgO}$ dosage is beneficial for the metallurgical properties of pellet such as softening/melting properties, RSI and RDI and so on. However, the strength of $\mathrm{MgO}$ flux pellet determined by the induration process appears to gradually attenuate with the addition of $\mathrm{MgO}$ content. Hence, a detailed study about induration of $\mathrm{MgO}$ flux pellet is a fundamental task to make $\mathrm{MgO}$ utilized efficiently. At present, the induration process of $\mathrm{MgO}$ flux pellet is rarely reported. Unlike sinter agglomerated by the binding phase, pellet induration is conducted maintaining the pellet in the solid state, which includes the oxidation of $\mathrm{Fe}_{3} \mathrm{O}_{4}$ and the sintering densification of pellet $[15,16]$. These processes are the main reasons resulting in the pellet's shrinkage, densification and high strength. Similarly, Sandeep Kuma et al. [17,18] reported that both the oxidation process of magnetite to hematite and the sintering process of hematite are vital for pellet induration, the rates of these two processes not only depend on the thermal and gaseous environment when the pellet gets exposed in the induration reactor, but also interdependent on each other.

In the present work, the induration process of $\mathrm{MgO}$ flux pellet was analyzed and discussed in aspects of oxidation process of $\mathrm{Fe}_{3} \mathrm{O}_{4}$ into $\mathrm{Fe}_{2} \mathrm{O}_{3}$ and densification process of pellet. Therefore, this work actually consists of two parts, one is the influence of $\mathrm{MgO}$ on the oxidation of $\mathrm{Fe}_{3} \mathrm{O}_{4}$, and the other is the influence of $\mathrm{MgO}$ on the densification of pellet. First of all, in order to clarify the effect of $\mathrm{MgO}$ on the oxidation process of $\mathrm{Fe}_{3} \mathrm{O}_{4}$, the analytical reagent of $\mathrm{MgO}$ was used, and the analytical reagent of $\mathrm{Fe}_{3} \mathrm{O}_{4}$ was also adopted instead of magnetite iron ore in oxidation experiments. It is because that except for the iron oxide phase, the other gangue minerals also can be found in magnetite iron ore such as $\mathrm{SiO}_{2}, \mathrm{Al}_{2} \mathrm{O}_{3}$ etc. These gangue minerals may affect the experimental results if the magnetite iron ore is used as a raw material. Furthermore, an oxidation reaction model was proposed based on the unreacted core model theory to specify the oxidation process of $\mathrm{Fe}_{3} \mathrm{O}_{4}$. Secondly, pelletizing experiments using magnetite iron ore were also carried out in laboratory. The influence of $\mathrm{MgO}$ on the densification of pellet was then studied by investigating the development of pellet pores during the induration process. The target of this work is to reveal the induration mechanisms of $\mathrm{MgO}$ flux pellet and provide a reliable control strategy of the induration process for the $\mathrm{MgO}$ flux pellet. 


\section{Materials and Methods}

\subsection{Raw Materials}

In the current work, in order to avoid the influence of other gangue minerals in magnetite iron ore, the analytical reagents $\left(\mathrm{MgO}\right.$ and $\left.\mathrm{Fe}_{3} \mathrm{O}_{4}\right)$ produced by Sinopharm Group (Beijing, China) were selected instead of magnetite iron ore to prepare reagent ball and study the oxidation of $\mathrm{Fe}_{3} \mathrm{O}_{4}$ in the oxidation experiments. The analytical reagent with a purity of $99.99 \%$ is pure enough to assure the accuracy of the oxidation experiments. Besides, magnetite iron ore, bentonite, and light-burned magnesia (produced by burning the magnesite in $850{ }^{\circ} \mathrm{C}$ for $1 \mathrm{~h}$ ) were used for the pelletizing experiments to discover the densification process of $\mathrm{MgO}$ flux pellet. The chemical composition of pelletizing materials is listed in Table 1. Magnetite iron ore, Bentonite and light-burned magnesia contained in the pelletizing materials were used for the Fe source, the binding media, and adjusting $\mathrm{MgO}$ content in pellet, respectively. Actually, the light-burned magnesia is an $\mathrm{MgO}$ bearing flux prepared by an elementary roasting with magnesite. The samples agglomerated with analytical reagent are named as reagent ball (base reagent ball or $\mathrm{MgO}$ bearing reagent ball), while agglomerated with the magnetite iron ore, the bentonite, and the light-burned magnesia are named as pellet (Non-MgO flux pellet or $\mathrm{MgO}$ flux pellet).

Table 1. Chemical composition of pelletizing materials for pellet, wt \%.

\begin{tabular}{cccccccc}
\hline Pelletizing Materials & $\mathbf{T F e}$ & $\mathbf{M g O}$ & $\mathbf{C a O}$ & $\mathbf{S i O}_{2}$ & $\mathbf{A l}_{\mathbf{2}} \mathbf{O}_{\mathbf{3}}$ & $\mathbf{K}_{\mathbf{2}} \mathbf{O}+\mathbf{N a}_{\mathbf{2}} \mathbf{O}$ & $\mathbf{L O I}$ \\
\hline Magnetite iron ore & 65.5 & 0.14 & 0.56 & 5.07 & 0.12 & - & - \\
Light-burned magnesia & - & 84.50 & 1.2 & 3.11 & 0.72 & - & 9.32 \\
Bentonite & 1.93 & 0.16 & 0.55 & 70.89 & 19.65 & 4.45 & - \\
\hline
\end{tabular}

Note: LOI-loss on ignition.

The particle size of the pelletizing materials was analyzed using the MASTERSIZER2000 laser particle size analyzer (Malvern Instruments, Malvern, UK) seen in Figure 1. At present, there is no explicit ISO standard about the particle size of iron ore for pelletizing. In the national standard of China [19], it is required that portion of the particles size less than $74 \mu \mathrm{m}(-74 \mu \mathrm{m})$ should overtop $80 \%$. From Figure 1, the particle size of the pelletizing materials is fine enough to meet pelletizing demands.

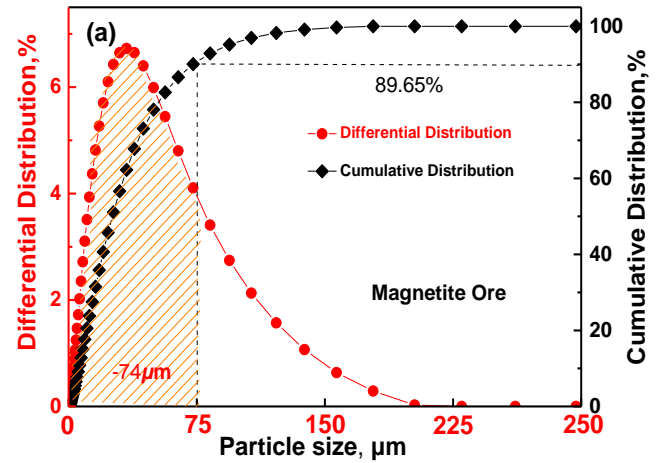

(a)

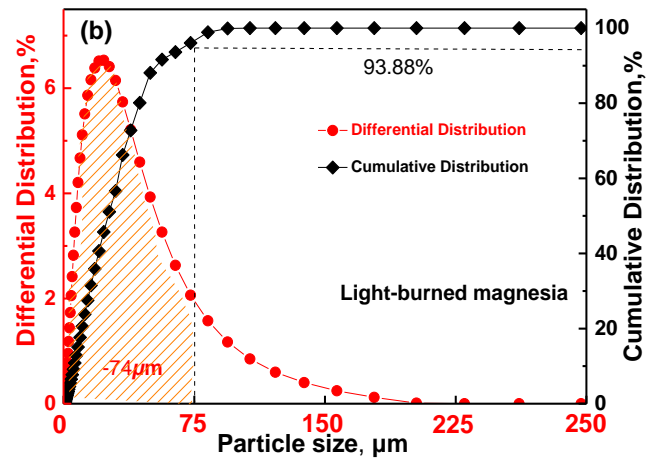

(b)

Figure 1. Cont. 


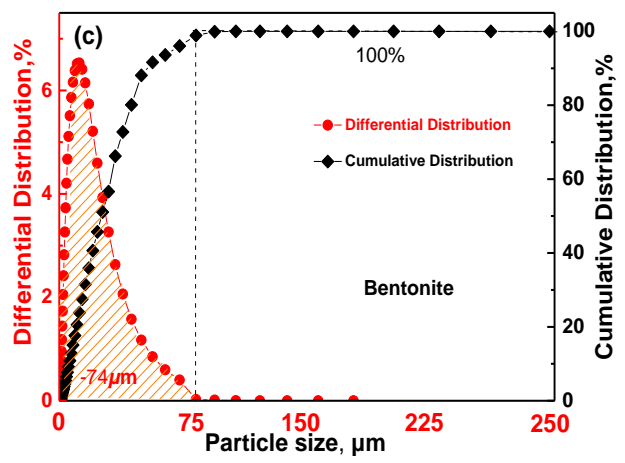

(c)

Figure 1. Particle size of pelletizing materials (a) magnetite iron ore; (b) light-burned magnesia; (c) bentonite.

\subsection{Experimental Methods}

\subsubsection{Oxidation Process of $\mathrm{Fe}_{3} \mathrm{O}_{4}$}

To eliminate the influence of gangue minerals contained in magnetite iron ore, the analytical reagents of $\mathrm{Fe}_{3} \mathrm{O}_{4}$ and $\mathrm{MgO}$ were chosen to prepare reagent ball. The preparing and firing of the reagent ball were successively carried out.

(1) Preparing of the reagent ball. The reagent ball was prepared via pressing equipment (Q-500, Shenyang Metals Equipment, Shenyang, China). Generally, the desired MgO dosage in pellet production should not be too high so that the pellet can maintain a higher iron grade. Therefore, three kinds of reagent ball including base reagent ball $\left(w_{(\mathrm{Fe} 3 \mathrm{O} 4)}=100 \%\right), 2.5 \% \mathrm{MgO}$ bearing reagent ball $\left(w_{(\mathrm{Fe} 3 \mathrm{O} 4)} / w_{(\mathrm{MgO})}=97.5 \% / 2.5 \%\right)$, and $5.0 \% \mathrm{MgO}$ bearing reagent ball $\left(w_{(\mathrm{Fe} 3 \mathrm{O} 4)} / w_{(\mathrm{MgO})}=95.0 \% / 5.0 \%\right)$ were designed to contrastively clarify the effect of $\mathrm{MgO}$ on the oxidation of $\mathrm{Fe}_{3} \mathrm{O}_{4}$. A general view of the pressing reagent ball process is shown in Figure 2. The diameter of the reagent sample is $12 \mathrm{~mm}$ and the weight of per reagent ball is $6 \pm 0.2 \mathrm{~g}$.
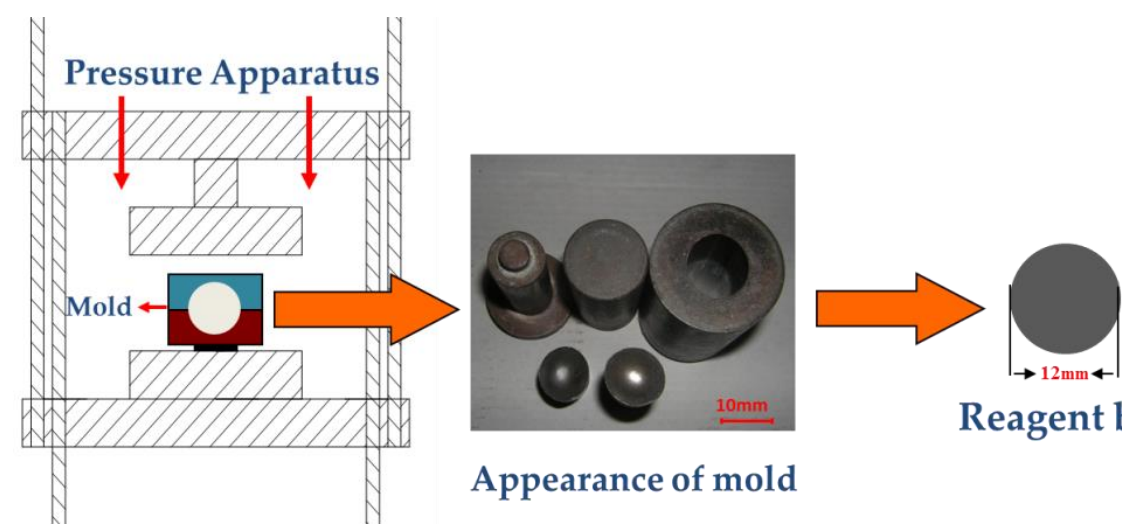

Appearance of mold

Reagent ball

Figure 2. Preparing process of the reagent ball.

(2) Firing of the reagent ball. The reagent ball was fired at oxidizing atmosphere to simulate the induration process of pellet. The schematic drawing of equipment is shown in Figure 3. Electric balance (ME204, Mettler Toledo, Zurich, Switzerland) was used to record the weight increment of reagent ball in firing process. The relation between oxidation ratio of $\mathrm{Fe}_{3} \mathrm{O}_{4}(Y)$ and time $(t)$ was then plotted. The detailed experimental conditions are shown as follows. Firing temperature: $1250{ }^{\circ} \mathrm{C}$; weight of total samples: $120 \pm 4 \mathrm{~g}$ (Totally, 20 reagent balls were adopted); Accuracy of balance: $0.0001 \mathrm{~g}$; oxidizing gas flow $\left(\mathrm{O}_{2}: \mathrm{N}_{2}=1: 4\right): 15 \mathrm{~L} / \mathrm{min}$. 


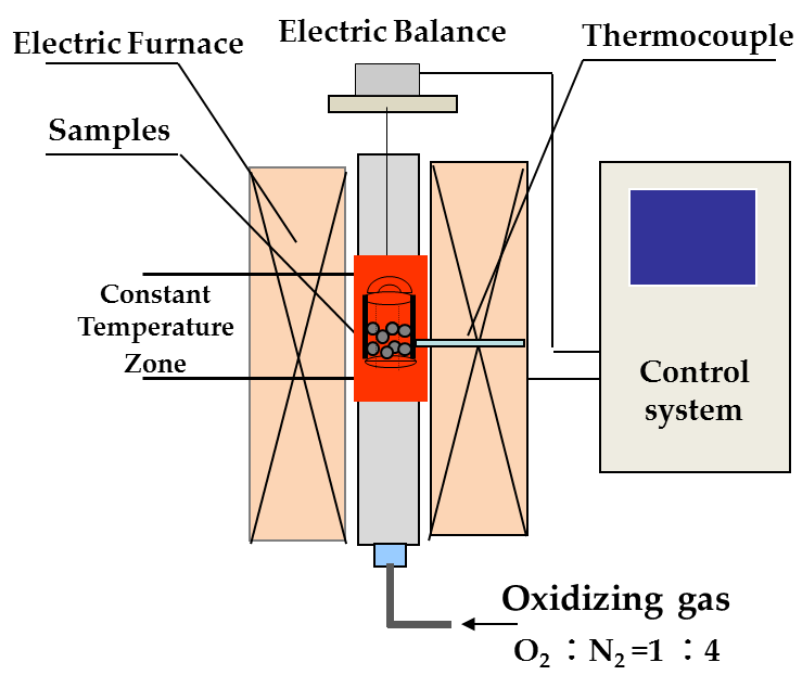

Figure 3. Schematic drawing of firing equipment.

The weight increment of the samples (reagent ball) is recorded during the experiments of oxidation from $\mathrm{Fe}_{3} \mathrm{O}_{4}$ into $\mathrm{Fe}_{2} \mathrm{O}_{3}$. The detailed reaction is shown in Equation (1):

\begin{tabular}{|c|c|c|c|c|c|}
\hline \multicolumn{6}{|c|}{$\mathrm{Fe}_{3} \mathrm{O}_{4}(\mathrm{~s})+(1 / 4) \mathrm{O}_{2}(\mathrm{~g})=(3 / 2) \mathrm{Fe}_{2} \mathrm{O}_{3}$} \\
\hline \multirow{3}{*}{ Molar mass: } & $\mathrm{Fe}_{3} \mathrm{O}_{4}$ & $\rightarrow$ & $(3 / 2) \mathrm{Fe}_{2} \mathrm{O}_{3}$ & $\rightarrow$ & $(1 / 4) \mathrm{O}_{2}-$ For increment \\
\hline & 232 & & & & 8 \\
\hline & $w_{0}$ & & & & weight increment (wa) \\
\hline
\end{tabular}

According to above, $w_{\mathrm{O}}=232 \times w_{\mathrm{a}} / 8$. Then, oxidation ratio of $\mathrm{Fe}_{3} \mathrm{O}_{4}(Y)=w_{\mathrm{O}} / w_{\text {Total }}$.

Where, $w_{\mathrm{O}}$ is the oxidation mass of $\mathrm{Fe}_{3} \mathrm{O}_{4}, w_{\mathrm{a}}$ is the weight increment, and $w_{\text {Total }}$ is the total mass of $\mathrm{Fe}_{3} \mathrm{O}_{4}$ calculated by designed reagent proportion.

Generally, the pore condition of iron ore green pellet (unfired) is an important dynamic condition for its firing and indurating. Therefore, it should be noted that the pressure of preparing the reagent ball was set on the basis of ensuring the similar porosity and pore distribution between the unfired reagent ball and the iron ore green pellet, which is carried out to confirm the similar dynamic condition during the fired induration for the reagent ball and the iron ore green pellet. The pressure condition was finalized at $10 \mathrm{MPa}$ for keeping 2 min according to the pore condition analysis by mercury injection apparatus (Auto pore IV9500, Micromeritics, Norcross, GA, USA).

\subsubsection{Preparing Pellet with Magnetite Iron Ore}

Except for the oxidation experiments with reagents, the pelletizing experiments with the pelletizing materials were carried out in laboratory. The pelletizing of iron ore is a consolidation method to obtain a high-strength pellet. This method contains granulation of the mixed materials (such as iron ore, bentonite, and flux) in a pelletizing disc, drying of green pellet, firing of green pellet, and air cooling finally. The pelletizing process is summarized in Figure 4.

In the pelletizing experiments, the portions of the light-burned magnesia in the pellet were designed at $0 \%, 1.5 \%$, and $3.0 \%$, the bentonite content in mixed pelletizing materials was kept at a constant of $1.0 \%$, and the magnetite iron ore portions were finalized according to the other two pelletizing materials mentioned above to ensure the total proportion of three kinds of pelletizing materials is $100 \%$. 


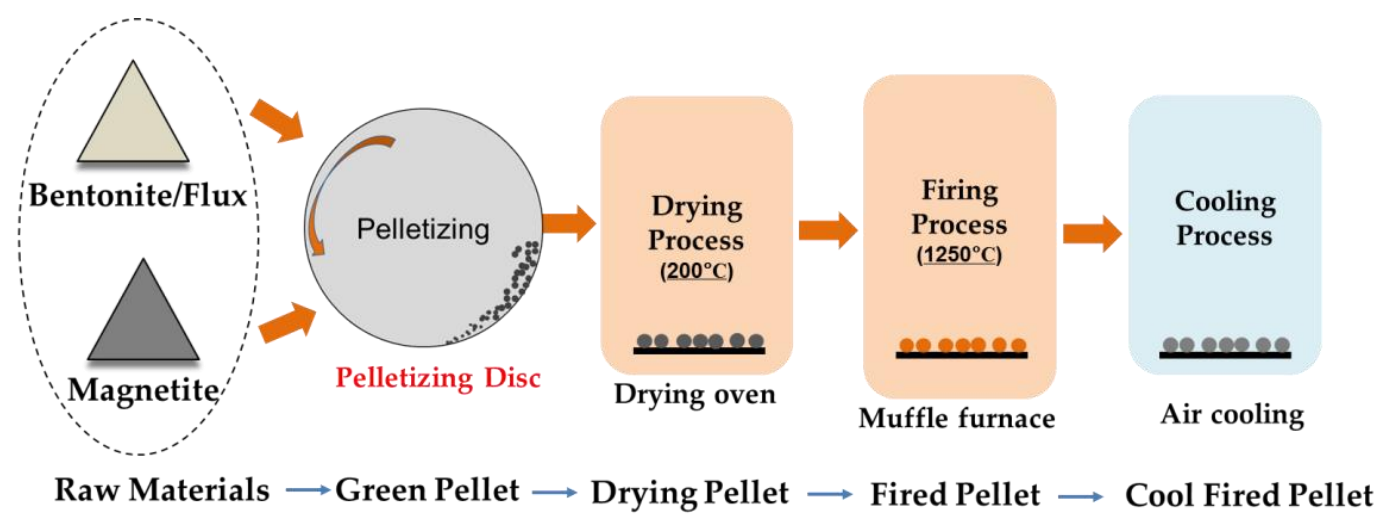

Figure 4. Pelletizing process of iron ore pellet.

The pelletizing parameters are listed as follows:

(a) Producing green pellet. The main parameters in this step include, $8.0 \pm 0.5 \%$ of moisture content in mixed raw materials, $30 \mathrm{~min}$ of pelletizing time, and $12.0 \mathrm{~mm}$ of size for the green pellet;

(b) Drying of the green pellet. The green pellet is dried at $200^{\circ} \mathrm{C}$ for $3 \mathrm{~h}$ in a drying oven $(\mathrm{H}-201$, Kexiang Instrument Equipment, Anshan, China);

(c) Firing of the green pellet. In order to physically simulate the firing process of grate-rotary kiln in pellet plants, the dried pellet is put into a preheated muffle furnace (MF400, Great Wall Electronic Furnace, Shenyang, China) at $900^{\circ} \mathrm{C}$, and then the temperature of furnace is increased to $1250{ }^{\circ} \mathrm{C}$ and finally maintains at $1250{ }^{\circ} \mathrm{C}$ for $20 \mathrm{~min}$. In addition, the air is blasted into the furnace in $1.2 \mathrm{~L} / \mathrm{min}$ after the dried pellet is put in the furnace. The details of firing process are shown in Figure 5;

(d) Cooling of the fired pellet. Following the process of firing, the pellet is air-cooled to ambient temperature; the cooled pellet is so-called fired pellet;

(e) Compressive strength (CS) testing. The CS is detected according to the ISO4700 standard [19]; the general method is this: 64 selected pellets with diameter of $10-12.5 \mathrm{~mm}$ are tested in a compressive tester, the two maximum values and two minimum values are deleted; the average of the remaining 60 values is regarded as the final CS.

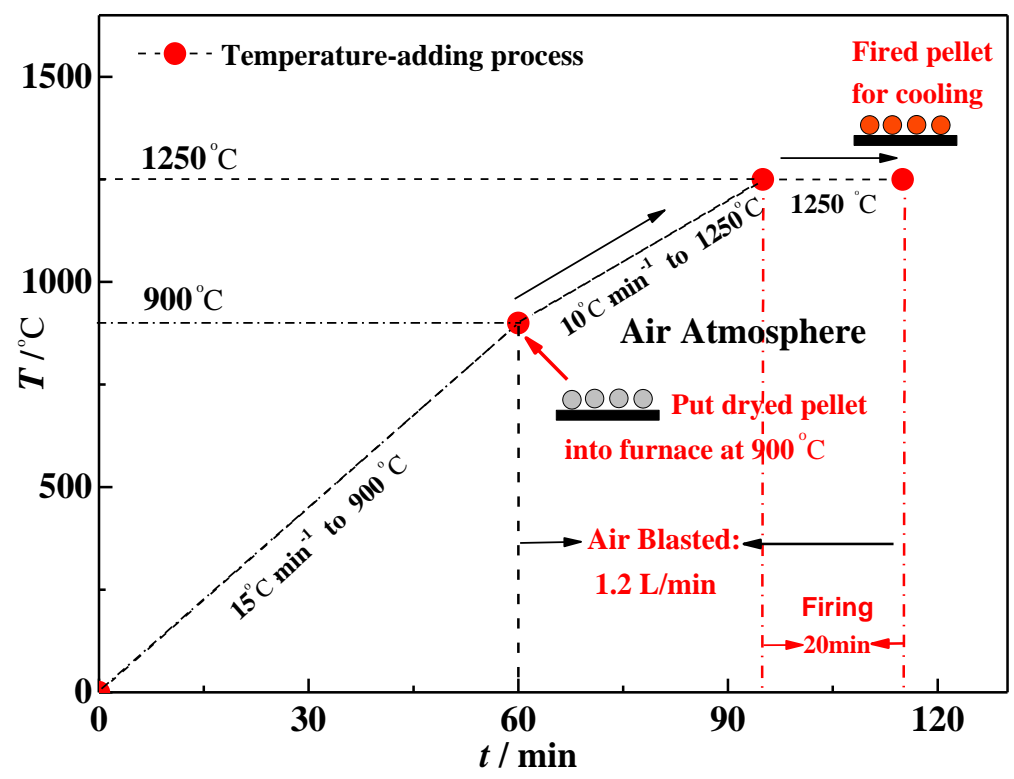

Figure 5. Firing system parameters. 


\subsubsection{Densification Process of Pellet}

The quality of magnetite pellet is primarily determined by the physical-chemical changes that the pellet undergoes as it makes excursion through the gaseous and thermal environment in the induration furnace. Among these physical-chemical processes, the oxidation of magnetite phase and the sintering of oxidized magnetite phase (hematite) are vital [17]. The reaction adheres to the following order:

$$
\mathrm{Fe}_{3} \mathrm{O}_{4} \longrightarrow \mathrm{Fe}_{2} \mathrm{O}_{3}
$$

\section{Cubic lattice Hexahedral lattice}

Simultaneously, the lattice transits from the cubic lattice to hexahedral lattice when the magnetite $\left(\mathrm{Fe}_{3} \mathrm{O}_{4}\right)$ is oxidized to hematite $\left(\mathrm{Fe}_{2} \mathrm{O}_{3}\right)$ [20], the volume of pellet gradually shrinks due to the sintering action. Then the pellet is dense and becomes the fired pellet which can meet the requirements of the BF process.

The pore parameters (porosity and pore distribution) for both the green pellet and the fired pellet were tested by a mercury injection apparatus (Auto pore IV9500, Micromeritics, Norcross, GA, USA). Effect of $\mathrm{MgO}$ on the densification process of the pellet was investigated according to the variation of porosity when the green pellet was fired into the fired pellet. Oxide densification index (ODI) was defined to describe the densification degree as Equation (2):

$$
\eta=\frac{\left|\varepsilon_{2}-\varepsilon_{1}\right|}{\varepsilon_{1}} \times 100 \%
$$

where, $\eta$ : oxide densification index (ODI), \%; $\varepsilon_{1}$ : porosity of green pellet; $\varepsilon_{2}$ : porosity of fired pellet. Generally, The ODI $\eta)$ is higher, the densification degree of the pellet is better, and then the strength of fired pellet may be favorable.

\subsubsection{Reproducible Experiment}

Reproducible experiments were carried out to improve the accuracy of the results. Both the oxidation experiments and the pelletizing experiments were repeated twice. The arithmetic mean of the two results was then used as the final result.

\section{Results}

\subsection{Effect of $\mathrm{MgO}$ on the Oxidation Process of $\mathrm{Fe}_{3} \mathrm{O}_{4}$}

The porosity and pore distribution for both the unfired reagent ball and the iron ore green pellet were contrastively tested to determine the pressure condition of preparing the reagent ball. The pore parameters and cross section images of two kinds of samples are shown in Figure 6. It is worthwhile mentioning that each result of porosity in Figure $6 a, b$ is repeated twice. The arithmetic mean of the two results is used as the final result. The results in Figure $6 a, b$ indicate that as the pressure of preparing reagent ball is confirmed at $10 \mathrm{MPa}$ for keeping $2 \mathrm{~min}$, the pore distribution and porosity between the unfired reagent ball and iron ore green pellet appears similar. One can also conclude from Figure $6 \mathrm{c}$ that the cross sections of both the unfired reagent ball and the iron ore green pellet are of similarity. It is consequently deemed that the reagent ball can well represent the iron ore pellet due to similar dynamic conditions (pore conditions). The oxidation experiment results of reagent ball are suitable to be referenced for iron ore pellet. In the study, we also pick up the conclusion that the porosity and pore distribution of all sorts of the green pellet (different light-burned magnesia dosage) are similar if the pelletizing materials (especially for iron ore and bentonite) are stable and the preparing green pellet parameters are the same. 

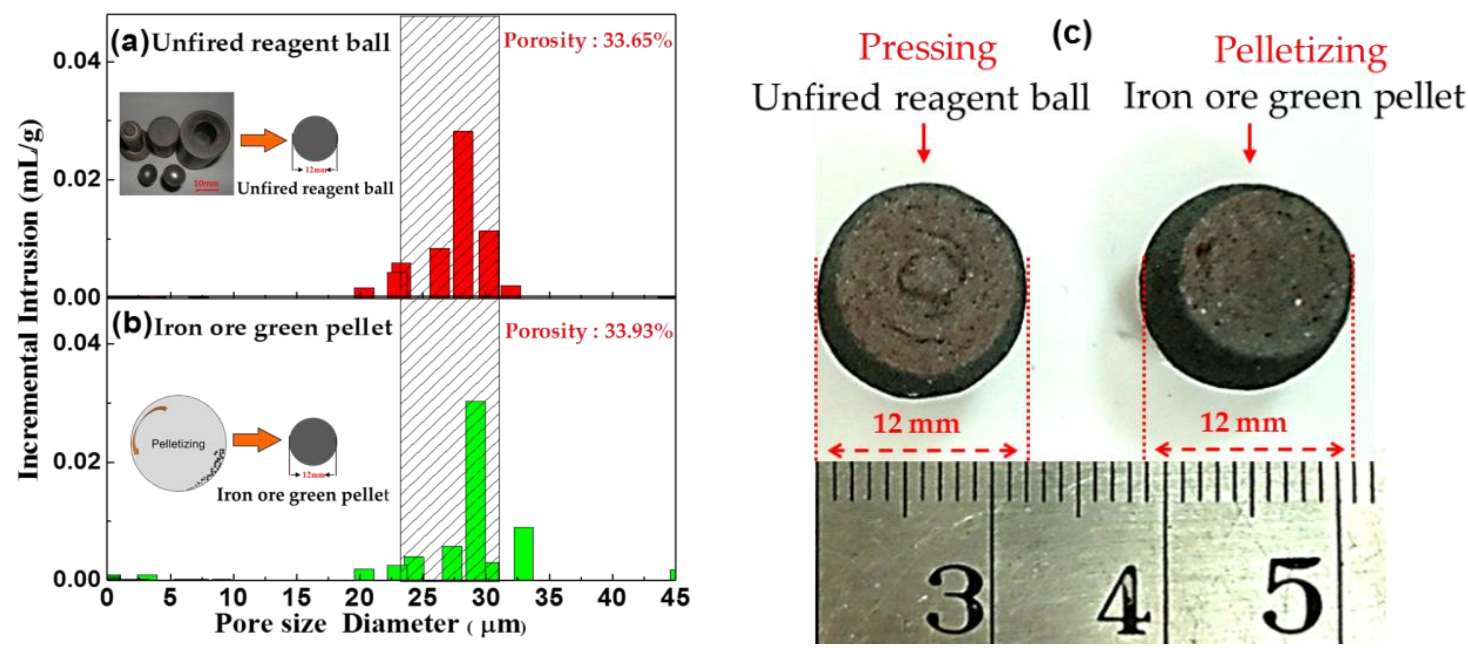

Figure 6. Pore parameters and cross section image of the unfired reagent ball and the iron ore green pellet (unfired): (a) unfired reagent ball; (b) Iron ore green pellet; (c) Cross section of unfired reagent ball and iron ore green pellet.

The relation between the $\mathrm{Fe}_{3} \mathrm{O}_{4}$ oxidation ratio $(Y)$ and time $(t)$ for different $\mathrm{MgO}$ portions in reagent ball is shown in Figure 7. It is concluded that as increasing of $\mathrm{MgO}$ from $0 \%$ to $5.0 \%$ the oxidation rate of $\mathrm{Fe}_{3} \mathrm{O}_{4}$ is gradually slower, especially at the range of $0 \sim 4 \mathrm{~min}$. The difference of the oxidation ratio $(\Delta Y)$ between the base reagent ball and $5.0 \% \mathrm{MgO}$ bearing reagent ball becomes larger in this range. $\mathrm{MgO}$ adversely affects the oxidation of $\mathrm{Fe}_{3} \mathrm{O}_{4}$.

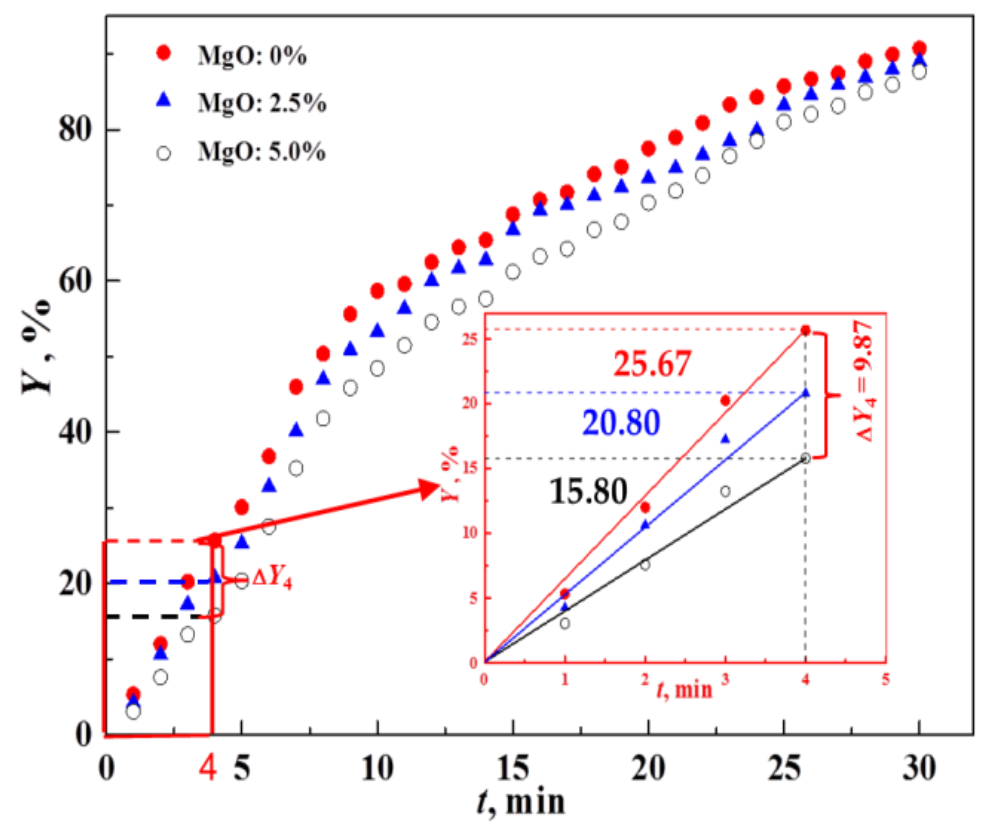

Figure 7. Oxidation ratio of $\mathrm{Fe}_{3} \mathrm{O}_{4}$.

The unreacted core model was used to discuss the reaction process for the oxidation of $\mathrm{Fe}_{3} \mathrm{O}_{4}$. Based on this model [21,22], the expression is shown in Equation (3):

$$
t^{*}=g_{F p}(Y)+\sigma_{\mathrm{s}}^{2} p_{F p}(Y)+\sigma_{\mathrm{s}}^{2} \frac{2 Y}{S h^{*}}
$$


In Equation (3): $t^{*}$, the time getting to oxidation ratio $(Y)$, is the sum of three processes which is controlled by three independent steps containing chemical reaction, internal diffusion, and external mass transfer. Therefore, for the right side of Equation (3), the $g_{F p}(Y)$ is chemical reaction control process; the $\sigma_{\mathrm{s}}^{2} p_{F p}(Y)$ is the internal diffusion control process; and the $\sigma_{\mathrm{s}}^{2} \frac{2 Y}{S h^{*}}$ is the external mass transfer control process.

Where, $t^{*}=\frac{b k C_{A b}}{\rho_{\beta}}\left(\frac{A_{p}}{F_{p} V_{p}}\right) t$, Non-dimensional time; $\sigma_{s}^{2}=\frac{k}{2 D_{e}}\left(\frac{V_{p}}{A_{p}}\right)$, unreacted core modules of shrinkage; $S h^{*}=\frac{k}{D_{e}}\left(\frac{F_{p} V_{p}}{A_{p}}\right)$, Modified Sherwood number; $g_{F p}(Y)$ and $p_{F p}(Y)$ are the function of conversion percent $(Y) ; g_{F p} Y=1-(1-Y)^{1 / F_{p}}$

$$
\left.\begin{array}{rlr}
p_{F P}(Y) & =Y^{2} & \\
& =Y+(1+Y) \ln (1-Y) & F_{p}=1 \\
& =1-3(1-Y)^{2 / 3}+2(1-Y) & F_{p}=3
\end{array}\right\}
$$

$A_{p}$ and $V_{p}$ is the surface area and volume of the solid pellet. $D_{e}$ is the diffusion coefficient. $k$ is the interface reaction rate constant. $C_{A b}$ is the gas-reactant concentration. $\rho_{\beta}$ is the density of the solid pellet. $b$ is the number of molecules $\{\mathrm{A}(\mathrm{g})+b \mathrm{~B}(\mathrm{~s}) \longrightarrow \mathrm{P}\} . F_{p}$ is the shape factor of solid particles (for the infinite plate, $F_{p}=1$; for the cylinder, $F_{p}=2$; for the sphere, $F_{p}=3$ ).

In this work, some known parameters are obviously utilized. For example, the diameter is $12 \mathrm{~mm}$, the $A_{p}$ and $V_{p}$ can be calculated based on sample diameter, $b=4\left\{\mathrm{O}_{2}(\mathrm{~g})+4 \mathrm{Fe}_{3} \mathrm{O}_{4}(\mathrm{~s})=6 \mathrm{Fe}_{2} \mathrm{O}_{3}\right\}$. Also, some assumptions were designed as follows, (a) external mass transfer resistance is ignored, which means that gas is easy to reach the surface of solid phase, so the $\sigma_{\mathrm{s}}^{2} \frac{2 Y}{S h^{*}}$ in the right side of Equation (3) is omitted; (b) The reagent ball is absolutely sphere and then the $F_{p}=3$; (c) The $\rho_{\beta}$ is the same for all kinds of reagent ball; (d) The exothermic oxidation in the oxidation experiments is ignored.

The relation between oxidation ratio of $\mathrm{Fe}_{3} \mathrm{O}_{4}(Y)$ and time $(t)$ in $1250{ }^{\circ} \mathrm{C}$ was proposed base on the unreacted core model shown in Equations (5) and (6):

$$
\begin{aligned}
& \text { base reagent ball: } t=49.93-14.50 \times(1-Y)^{1 / 3}-110.57 \times(1-Y)^{2 / 3}+75.35 \times(1-Y) \\
& 5.0 \% \mathrm{MgO} \text { bearing reagent ball: } t=60.21-22.17 \times(1-Y)^{1 / 3}-126.08 \times(1-Y)^{2 / 3}+85.23 \times(1-Y)
\end{aligned}
$$

In order to verify the accuracy of the model, verification experiments were carried out. Under the condition of the model above, both the base reagent ball and 5.0\% $\mathrm{MgO}$ bearing reagent ball were fired for $35 \mathrm{~min}$. Then two kinds of samples were taken out to test the chemical composition. Based on the remaining $\mathrm{Fe}_{3} \mathrm{O}_{4}$ content of the fired samples in the verification experiments, it could obtain the oxidation ratio of $\mathrm{Fe}_{3} \mathrm{O}_{4}(Y)$ which is $92.06 \%$ for base reagent ball, and $96.26 \%$ for $5.0 \% \mathrm{MgO}$ bearing reagent ball. Comparably, according to the unreacted core model shown in Equations (5) and (6), the calculated value of $Y$ is $92.47 \%$ for base reagent ball, and $95.93 \%$ for $5.0 \% \mathrm{MgO}$ bearing reagent ball. Obviously, the experimental data and calculated values by the model are coincidentally well. Therefore, the unreacted core model can well describe the oxidation of $\mathrm{Fe}_{3} \mathrm{O}_{4}$ in the pellet induration process.

Furthermore, it can be calculated from Equations (5) and (6) that the oxidation of $\mathrm{Fe}_{3} \mathrm{O}_{4}$ for the base reagent ball will be completed at $49.93 \mathrm{~min}$, while this value goes to $60.21 \mathrm{~min}$ for the $5.0 \% \mathrm{MgO}$ bearing reagent ball. These results substantively verify the conclusion that $\mathrm{MgO}$ adversely affects the oxidation of $\mathrm{Fe}_{3} \mathrm{O}_{4}$. Moreover, The XRD analyses were performed to determine the main phase changes in the oxidation process. For convenient contrast, the reagent balls were fired at the same time (15 min). The XRD pattern is shown in Figure 8. It can be seen from Figure 8 that the $\mathrm{Fe}_{2} \mathrm{O}_{3} \mathrm{peak}$ strength of base reagent ball is stronger than that of $5.0 \% \mathrm{MgO}$ bearing reagent ball. Obviously, some of $\mathrm{Fe}_{3} \mathrm{O}_{4}$ is still un-oxidized in $5.0 \% \mathrm{MgO}$ bearing reagent ball, the MF phase $\left\{\left(\mathrm{Fe}_{x} \cdot \mathrm{Mg}_{1-x}\right) \mathrm{O} \cdot \mathrm{Fe}_{2} \mathrm{O}_{3}\right.$, $x=0.36\}$ is of existence. 


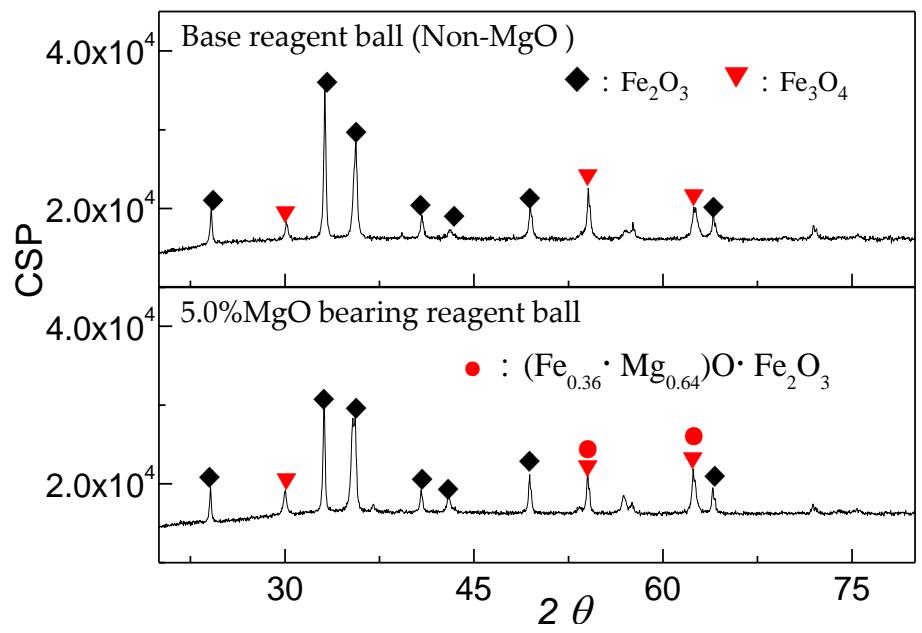

Figure 8. XRD patterns of reagent ball (fired for $15 \mathrm{~min}$ ).

The presence of MF phase is also proven by the SEM analysis result with the $5.0 \% \mathrm{MgO}$ bearing reagent ball in Figure 9. Figure 9b,c proves that the elemental Fe and elemental $\mathrm{Mg}$ coexists in a mutual solution way, then generates MF phase shown in Figure 9e.
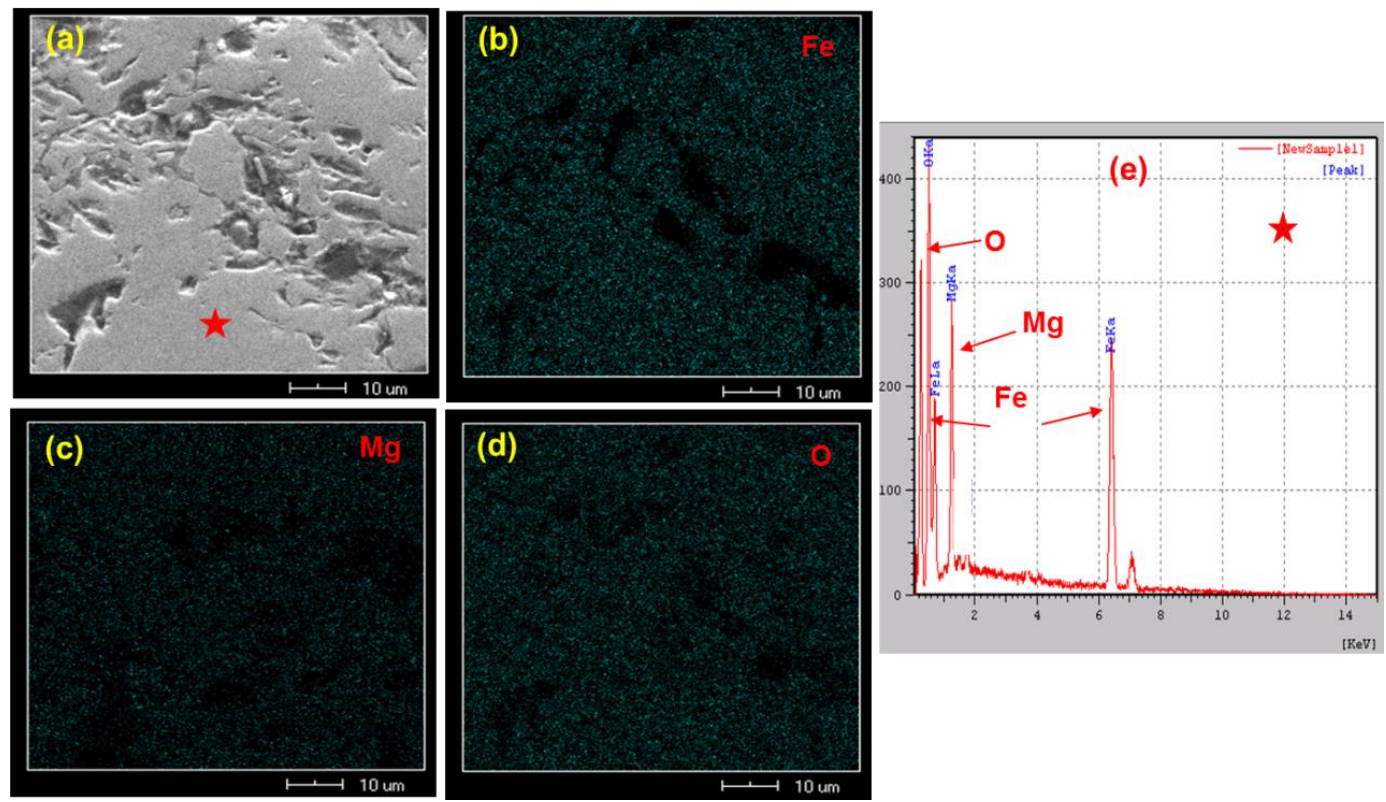

Figure 9. SEM photo and element distribution of 5.0\% MgO bearing reagent ball (a) SEM photo; (b) Fe element; (c) Mg element; (d) O element; (e) EDX analysis of/point.

The fired pellet in pelletizing experiments was polished and observed by optical microscopy (Axio Imager M2M, ZEISS, Oberkochen, Germany). The metallographic of the pellet is shown in Figure 10. In the figure, " $\mathrm{A}$ " phase (pale-white) is hematite $\left(\mathrm{Fe}_{2} \mathrm{O}_{3}\right)$; " $\mathrm{B}$ " phase (brown-gray) is magnetite and MF phase- $\left\{\left(\mathrm{Fe}_{x} \cdot \mathrm{Mg}_{1-x}\right) \mathrm{O} \cdot \mathrm{Fe}_{2} \mathrm{O}_{3}\right\}$; and "C" phase (charcoal-gray) is gangue minerals. It is seen that: (1) For Non-MgO flux pellet (Figure 10a), the recrystallization of $\mathrm{Fe}_{2} \mathrm{O}_{3}$ has done completely; (2) For $\mathrm{MgO}$ flux pellet (Figure $10 \mathrm{~b}, \mathrm{c}$ ), the $\mathrm{Fe}_{2} \mathrm{O}_{3}$ crystals is relatively less and uneven.

In order to pick up the detailed quantitative of each mineral phase in the iron ore pellet, the color aberration method via a software (Image-pro plus 6.0, Media Cybernetics, Rockville, MD, USA) was adopted. Actually, the color aberration method is a statistical calculation method. 

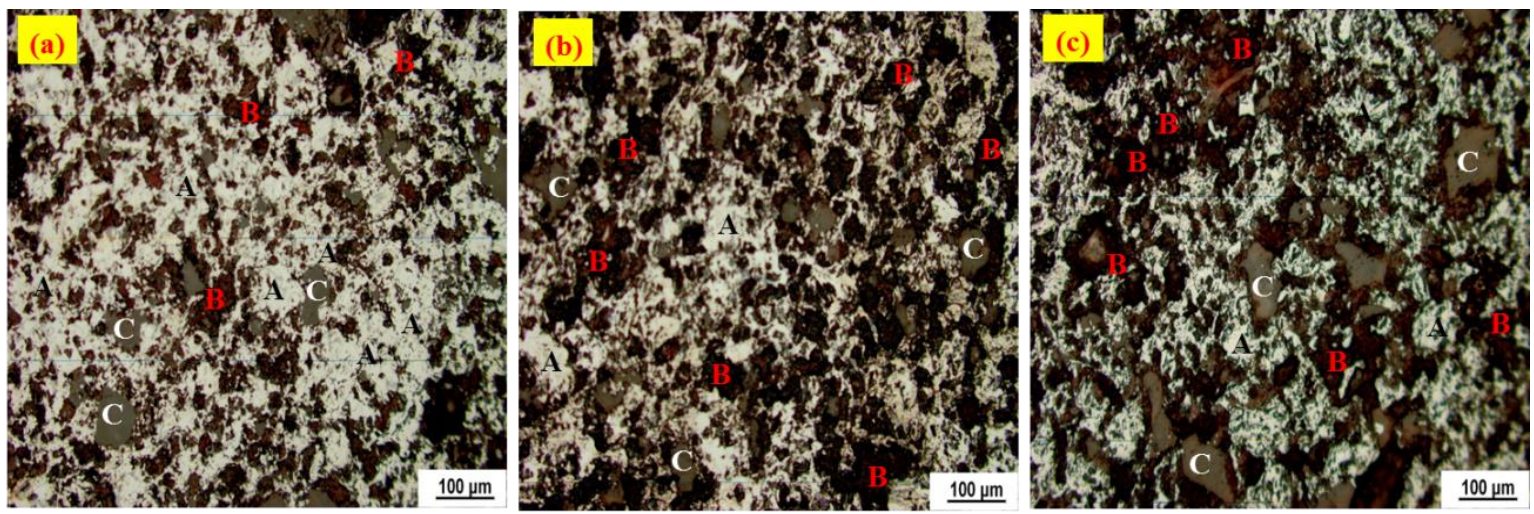

Figure 10. Metallographic of pellet (a) $0 \%$ of light-burned magnesia; (b) 1.5\% light-burned magnesia; (c) 3.0\% of light-burned magnesia. A: Hematite; B: Magnetite and MF phase; C: Gangue minerals.

For convenient explanation of color aberration method, a concrete example is shown in Figure 11. According to the color difference of each phase in Figure 11a, the software will compute the portion of each phase with different color (Red, Yellow, and Green) in Figure 11b-d.
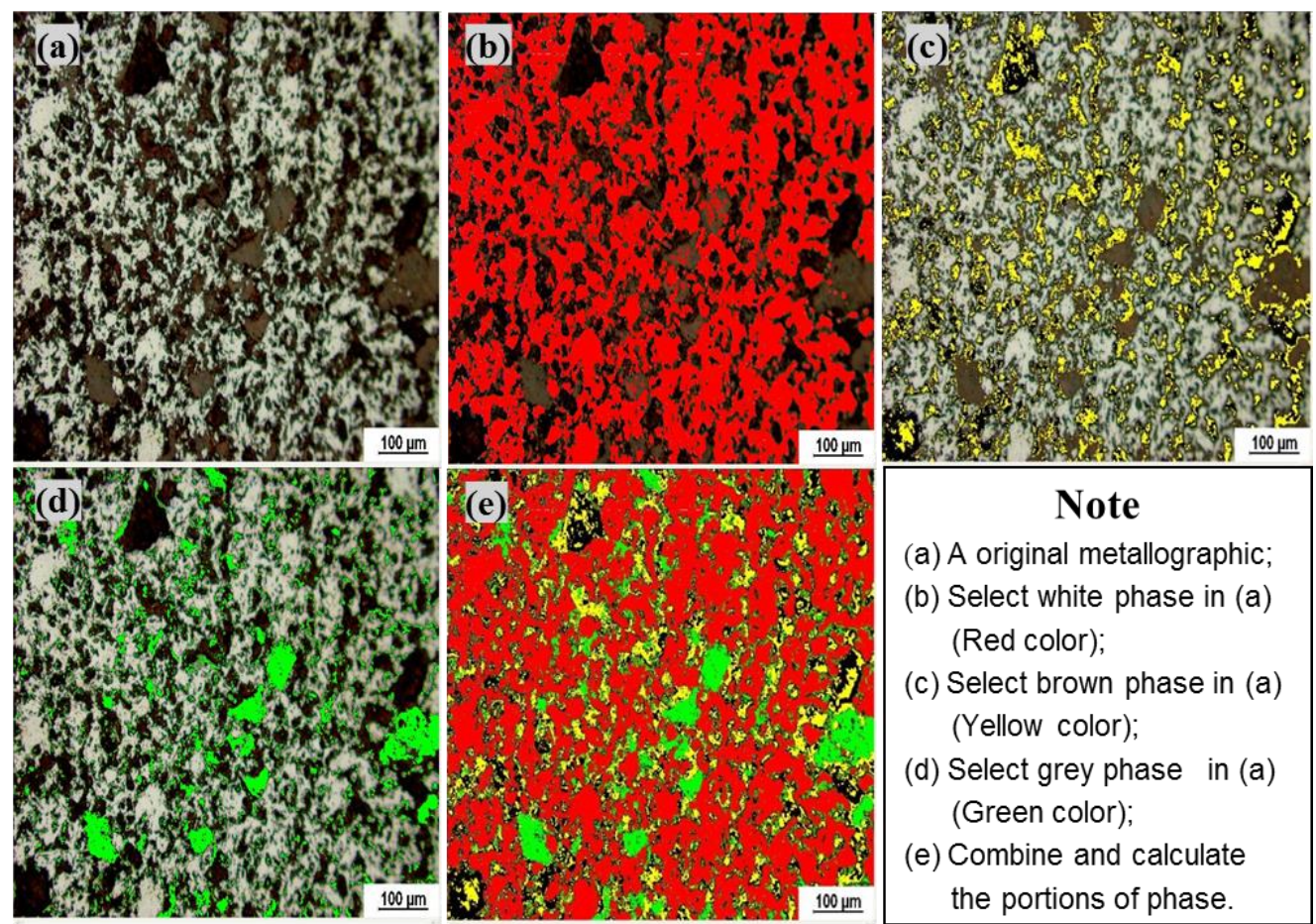

\section{Note}

(a) A original metallographic;

(b) Select white phase in (a) (Red color);

(c) Select brown phase in (a) (Yellow color);

(d) Select grey phase in (a) (Green color);

(e) Combine and calculate the portions of phase.

Figure 11. An example of color aberration method.

Based on the color aberration method, the detailed quantitative of the mineral composition in the pellet can be obtained. Here, it is remarkable that four samples for each kind of pellet are selected for analysis via the color aberration method, and the arithmetic mean value of the four results is used as the final result. The standard deviation of the hematite portion using color aberration method is $2.39 \%$. The detailed mineral composition of different $\mathrm{MgO}$ dosage pellet is shown in Figure 12. Figure 12 illustrates that as the portion of light-burned magnesia increases from $0 \%$ to $3.0 \%$, the hematite $\left(\mathrm{Fe}_{2} \mathrm{O}_{3}\right)$ content decreases gradually from $85.22 \%$ to $72.34 \%$, and the magnetite and MF phase content increases from $5.27 \%$ to $17.83 \%$. These results indirectly prove that the $\mathrm{MgO}$ dosage restrains the oxidation of $\mathrm{Fe}_{3} \mathrm{O}_{4}$ into $\mathrm{Fe}_{2} \mathrm{O}_{3}$. 


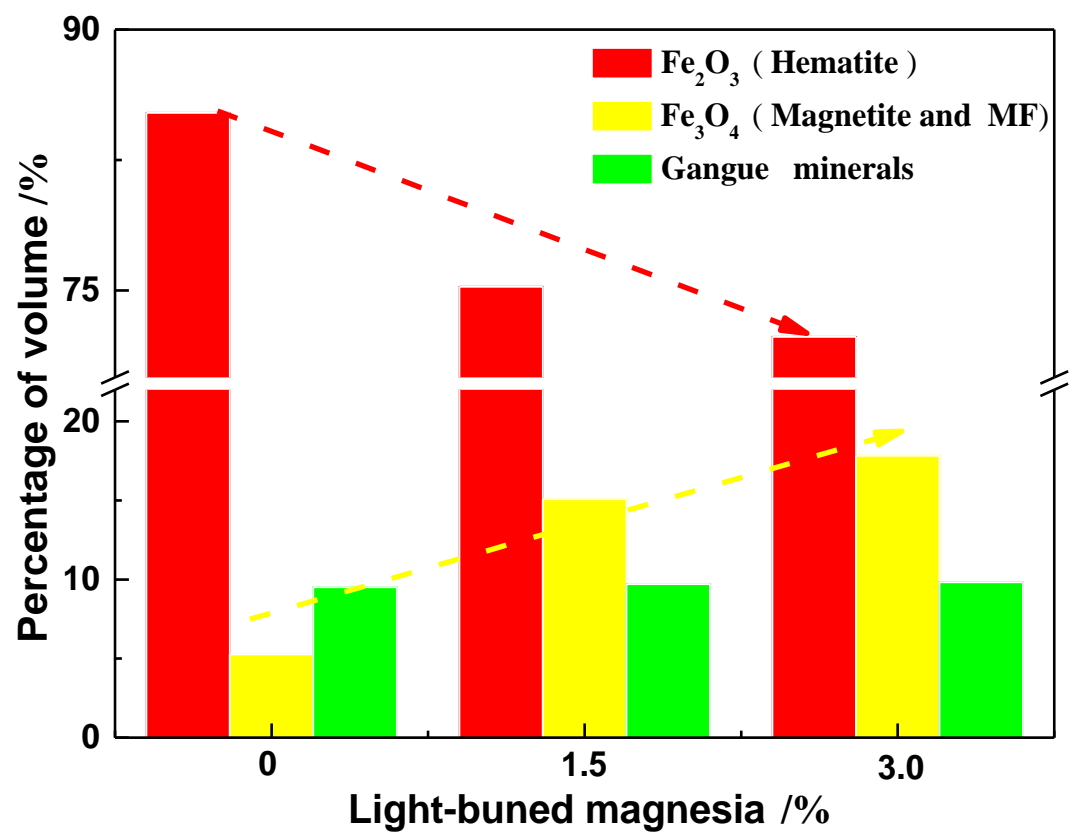

Figure 12. Effect of light-burned magnesia dosage on the mineral composition of iron ore pellet.

Summarily, both the oxidation experiments with reagent ball and the pelletizing experiments with magnetite iron ore have proven that $\mathrm{MgO}$ negatively affects the oxidation of $\mathrm{Fe}_{3} \mathrm{O}_{4}$; this phenomenon is unfavorable for the pellet induration process.

\subsection{Effect of $\mathrm{MgO}$ on the Densification Process of Pellet}

Effect of $\mathrm{MgO}$ on the pellet densification was investigated based on the changes of porosity and pore size distribution between the green pellet and fired pellet. The experimental results are shown in Figure 13. It should be noted that the porosity of the first sample is tested four times to obtain the standard deviation of the testing (here is $1.03 \%$ ), which means that the testing accuracy of porosity is higher enough. Therefore, for the other samples, each testing result of porosity is repeated twice and finalized in the arithmetic mean of the two results.

Figure 13 shows that during the induration process (from green pellet to fired pellet), both the pore size and porosity of the pellet decrease gradually, the structure of the pellet becomes dense. The pore-shrinkage and densification of $\mathrm{MgO}$ flux pellet are lower. For example, the porosity of Non-MgO flux pellet (fired pellet) decreases by $16.05 \%$ compared with that of green pellet and the pore size of fired pellet mainly distributes in 0-10 $\mu \mathrm{m}$ (Figure 13a). However, the porosity of $\mathrm{MgO}$ flux pellet decreases by $9.03 \%$ and the pore size of the fired pellet mainly distributes in 10-20 $\mu \mathrm{m}$ (Figure 13c). Moreover, as the proportion of light-burned magnesia increases from $0 \%$ to $3.0 \%$, the pore size of the fired pellet obviously increases and the porosity increases from $18.61 \%$ to $24.77 \%$.

Oxide densification index (ODI) of the pellet calculated by Equation (2) is shown in Figure 14. It is indicated from Figure 14 that the ODI $(\eta)$ decreases from $46.3 \%$ to $26.7 \%$ with the increasing of light-burned magnesia portion from $0 \%$ to $3.0 \%$. There is no doubt that $\mathrm{MgO}$ plays a negative role in the densification process. 


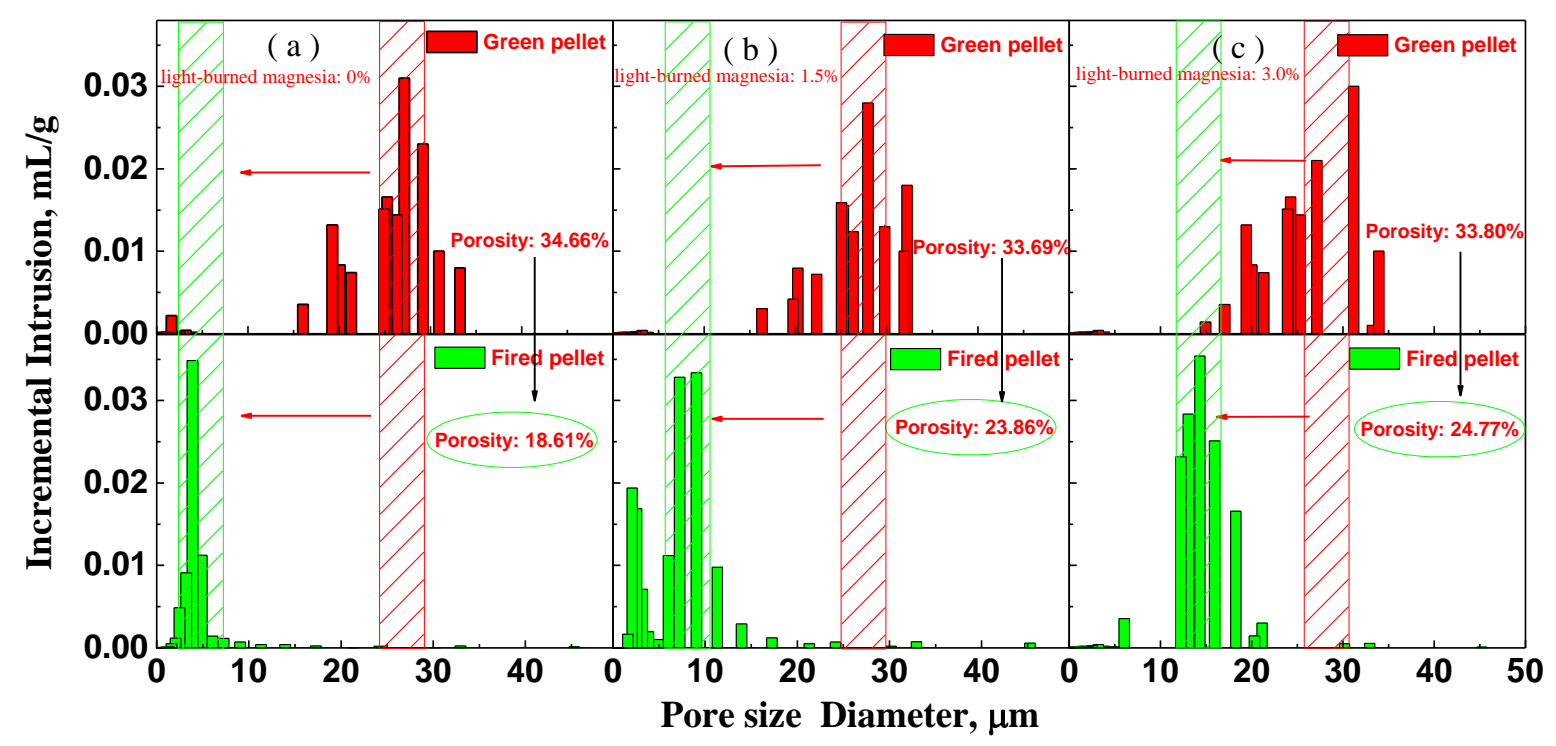

Figure 13. Variation of porosity and pore distribution of the pellet during the induration process (a) $0 \%$ of light-burned magnesia; (b) 1.5\% of light-burned magnesia; (c) 3.0\% of light-burned magnesia.

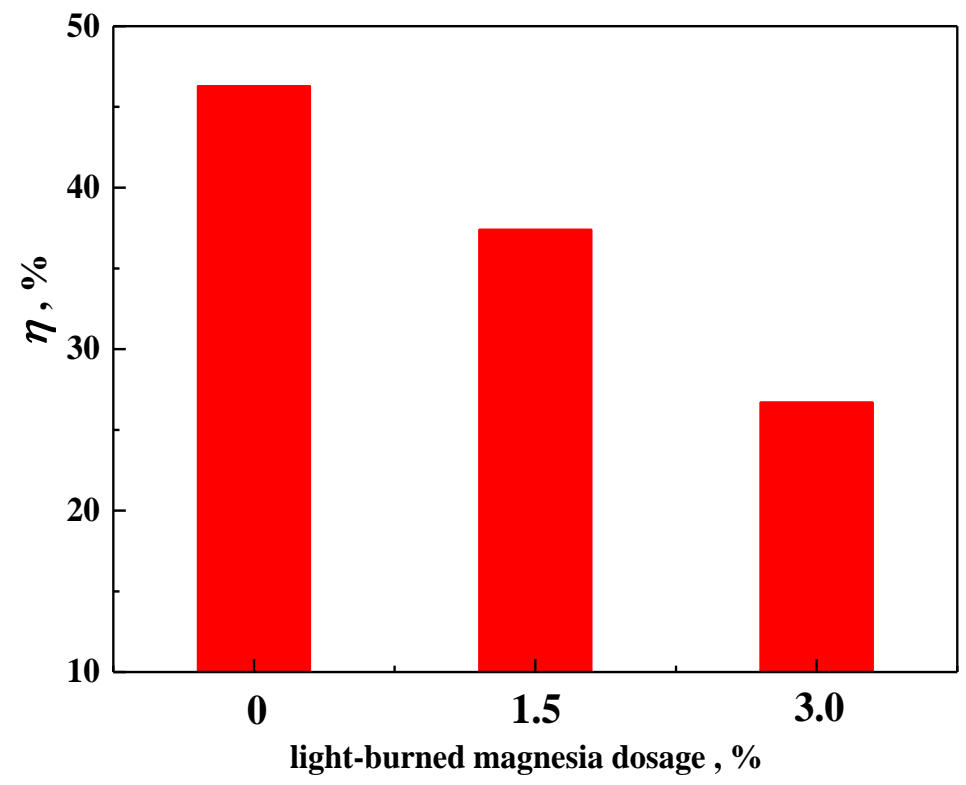

Figure 14. Effect of $\mathrm{MgO}$ on ODI $(\eta)$ of the pellet.

$\mathrm{MgO}$ adversely affects the oxidation process of $\mathrm{Fe}_{3} \mathrm{O}_{4}$. Also, $\mathrm{MgO}$ has a drawback to reduce the densification process of the pellet. The macroscopic phenomenon is that the strength of $\mathrm{MgO}$ flux pellet appears lower. The enhancing process of compressive strength (CS) was studied and the results are shown in Figure 15. The enhancing rate of CS for the $\mathrm{MgO}$ flux pellet $(1.5 \%$ and $3.0 \%$ of light-burned magnesia) is slower than that for the Non-MgO flux pellet ( $0 \%$ of light-burned magnesia). It takes $20 \mathrm{~min}$ for Non-MgO flux pellet to obtain the desired CS (>2500 N/pellet [19]), while $35 \mathrm{~min}$ is needed for producing desired $\mathrm{MgO}$ flux pellet (3.0\% of light-burned magnesia). Therefore, prolonging the induration time is an available method to obtain desired CS for producing the $\mathrm{MgO}$ flux pellet. 


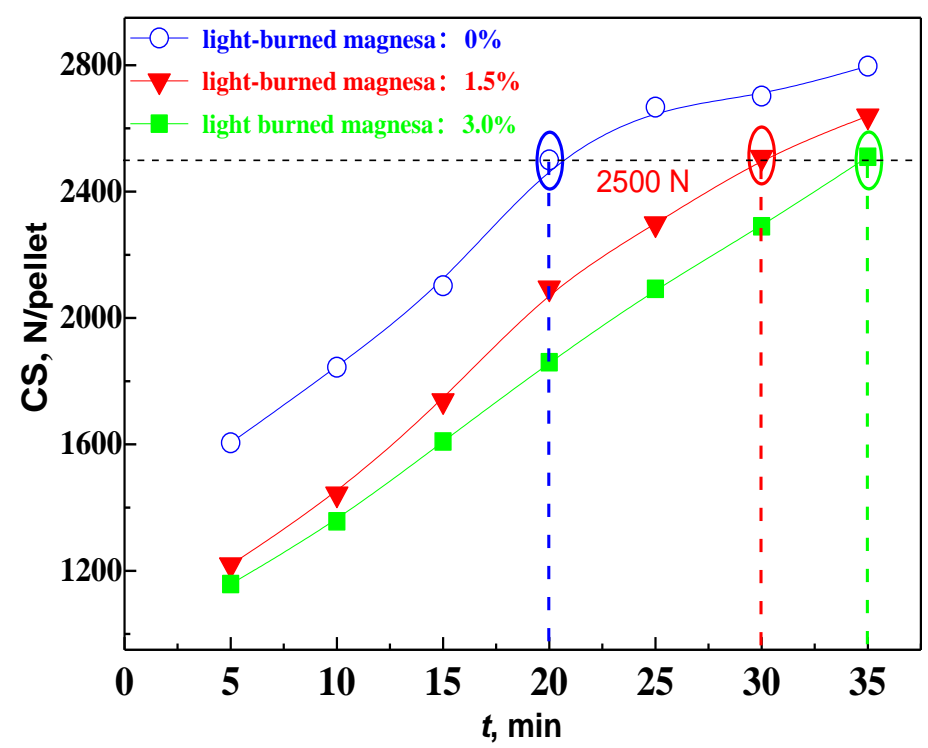

Figure 15. Enhancing process of pellet CS for different MgO dosage.

\section{Analysis and Discussion}

It is acknowledged that both the oxidation of magnetite $\left(\mathrm{Fe}_{3} \mathrm{O}_{4}\right)$ into hematite $\left(\mathrm{Fe}_{2} \mathrm{O}_{3}\right)$ and the sintering of hematite are important for pellet induration process. The lattice will also transit from cubic lattice to hexahedral lattice when the $\mathrm{Fe}_{3} \mathrm{O}_{4}$ is oxidized to $\mathrm{Fe}_{2} \mathrm{O}_{3}$. Because of sintering action and the lattice transition, the inner structure of pellet appears compact gradually and obtaining high strength. However, the $\mathrm{MgO}$ is found to impede the oxidation of $\mathrm{Fe}_{3} \mathrm{O}_{4}$ and then weak the densification behavior and lead to lower pellet strength. From $\mathrm{Fe}_{2} \mathrm{O}_{3}-\mathrm{MgO}$ phase diagram [23] shown in Figure 16. It is proven that the presence of $\mathrm{MgO}$ will low the temperature of which the hematite dissociates back into the magnetite, which means that the presence of $\mathrm{MgO}$ will make the dissociated temperature lower from hematite to magnetite or magnesioferrite (MF phase), and therefore, result in restraining the oxidation of magnetite $\left(\mathrm{Fe}_{3} \mathrm{O}_{4}\right)$ into hematite $\left(\mathrm{Fe}_{2} \mathrm{O}_{3}\right)$.

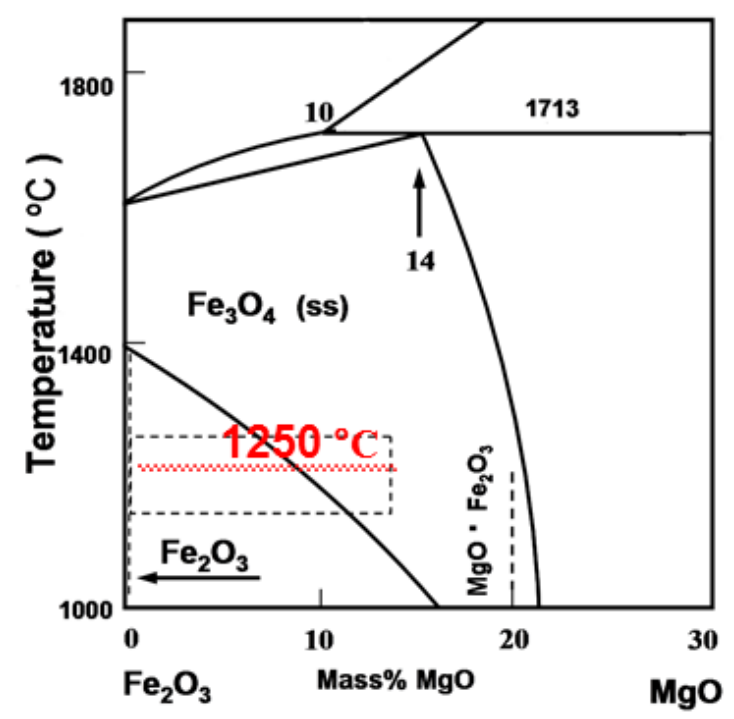

Figure 16. $\mathrm{Fe}_{2} \mathrm{O}_{3}-\mathrm{MgO}$ phase diagram.

The $\mathrm{Fe}^{2+}$ and $\mathrm{Mg}^{2+}$ can achieve a solid solution in the fired temperature of pellet (dotted line rectangle in Figure 16), which is also proved by the SEM analysis of MgO flux pellet in Figure 17. 
Figure 17 shows that most of the elemental $\mathrm{Mg}$ and elemental Fe distribute almost uniformly in iron oxide phase. That means the elemental Fe and elemental $\mathrm{Mg}$ coexists in the pellet in a mutual solution way. There is a reaction between $\mathrm{MgO}$ and $\mathrm{Fe}_{3} \mathrm{O}_{4}$, which will produce $\mathrm{MF}$ phase- $\left\{\left(\mathrm{Fe}_{x} \cdot \mathrm{Mg}_{1-x}\right)\right.$ $\left.\mathrm{O} \cdot \mathrm{Fe}_{2} \mathrm{O}_{3}\right\}$. It has been also found for $\mathrm{MF}-\left\{\left(\mathrm{Fe}_{x} \cdot \mathrm{Mg}_{1-x}\right) \mathrm{O} \cdot \mathrm{Fe}_{2} \mathrm{O}_{3}, x=0.36\right\}$ in $5.0 \% \mathrm{MgO}$ bearing reagent ball as shown in Figure 8, which is in accord with the phase diagram. The appearance of $\mathrm{MF}$ phase means that a part of $\mathrm{Fe}^{2+}$ is actually un-oxidized, which may result in the oxidation of $\mathrm{Fe}_{3} \mathrm{O}_{4}$ into $\mathrm{Fe}_{2} \mathrm{O}_{3}$ is impeded in a way. In addition, the $\mathrm{MF}$ phase has the same reverse spinel structure as the magnetite [10]. Consequently, the crystal transition from $\mathrm{Fe}_{3} \mathrm{O}_{4}$ to $\mathrm{Fe}_{2} \mathrm{O}_{3}$ existing in acid pellet is inhibited by $\mathrm{MF}$ phase. It may cause the uncompleted $\mathrm{Fe}_{2} \mathrm{O}_{3}$ recrystallization, limit the filling action of $\mathrm{Fe}_{2} \mathrm{O}_{3}$ crystal for the inner pore of pellet, and finally prevented the shrinkage and densification of the fired pellet. Therefore, $\mathrm{MgO}$ adversely affects the densification of pellets.
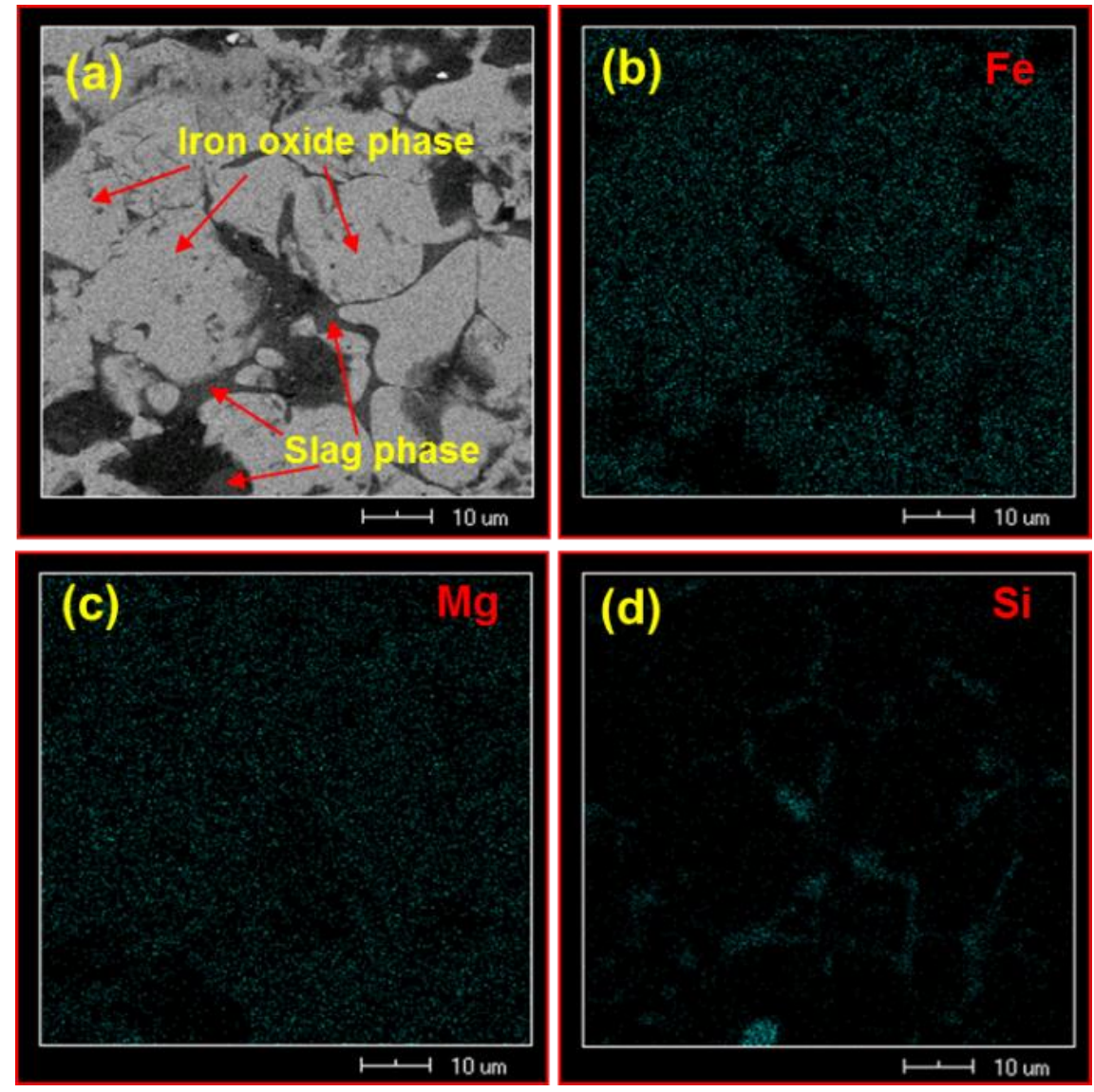

Figure 17. SEM photo and element distribution in $\mathrm{MgO}$ flux pellet ( $3 \%$ of light-burned magnesia) (a) SEM photo; (b) Fe element; (c) Mg element; (d) Si element.

In addition, it is generally acknowledged from the material mechanics theory that the material properties will be determined by the material inner structure $[24,25]$. In this article, it has been proven that the pore structure of a fired pellet changes gradually and porosity increases from $18.61 \%$ to $24.77 \%$ when the light-burned magnesia dosage increases from $0 \%$ to $3.0 \%$. According to the Griffith micro-crack theory [25], the relationship between the critical rupture stress $(\sigma)$ and the elastic modular ratio $(E)$ (i.e., the ratio of a normal stress to the corresponding normal strain) can be expressed as Equation (7):

$$
\sigma=Z \sqrt{\frac{E \gamma}{C}}
$$


where $\sigma$ is the critical rupture stress (MPa); $E$ is the elastic modular ratio (MPa); $Z$ is a correlation coefficient that is determined by the size and shape of the sample and its crack (dimensionless); $\gamma$ is the surface energy (J); and $C$ is the half-length of the crack (m).

The empirical formula expressing the relationship between the elastic modular ratio $(E)$ and the porosity $(\varepsilon)$ is shown in Equation (8) [26]:

$$
\frac{E}{E_{0}}=1-K_{1} \varepsilon+K_{2} \varepsilon^{2}
$$

where $E_{0}$ is the elastic modulus ratio of a sample without any pores (MPa); $K_{1}$ and $K_{2}$ are constants determined by the shape and direction of the cracks (dimensionless); $\varepsilon$ is the porosity (\%). If the $\varepsilon$ is relatively small, the last term $K_{2} \varepsilon^{2}$ in Equation (8) can thus be ignored. Therefore, the relationship between the critical rupture stress $(\sigma)$ and the porosity $(\varepsilon)$ can be then expressed as Equation (9):

$$
\sigma=Z \sqrt{\frac{E_{0}\left(1-K_{1} \varepsilon\right) \gamma}{C}}
$$

Equation (9) shows that the critical rupture stress $(\sigma)$ decreases when the porosity $(\varepsilon)$ of a pellet increases and the compressive strength of the pellet will consequently be diminished. additionally, if the pores are not evenly distributed in a pellet, they will assemble at the boundary of crystal grains, which may result in assembly stress, a bigger half-length $(C)$ of pores in a pellet, eventually, a lower critical rupture stress $(\sigma)$. Therefore, an increase in $\mathrm{MgO}$ content may result in an increase in the porosity of pellet; subsequently cause a decrease in the CS of the fired pellet.

In summary, some researches and trial practices $[4,27,28]$ have shown that the improvement of metallurgical properties, such as softening and melting properties, reduction swelling index (RSI), and low-temperature reduction disintegration (RDI) can be well achieved through $\mathrm{MgO}$ addition in the pellet. However, the results in current work indicate that $\mathrm{MgO}$ has a negative influence in the oxidation of $\mathrm{Fe}_{3} \mathrm{O}_{4}$ into $\mathrm{Fe}_{2} \mathrm{O}_{3}, \mathrm{MgO}$ is also found to inhibit the densification of pellet. Besides, in a previous study, Gao et al. stated that [29] $\mathrm{MgO}$ can rapidly diffuse and dissolve into $\mathrm{Fe}_{3} \mathrm{O}_{4}$; the diffusion rate can get to $13.64 \mu \mathrm{m} \cdot \mathrm{min}^{-1}$ at $1250{ }^{\circ} \mathrm{C}$, which means that $\mathrm{MgO}$ can diffuse into a $74 \mu \mathrm{m}$ magnetite iron ore particle in just $5 \mathrm{~min}$. Generally speaking, the induration time of pellet nowadays is much longer than $5 \mathrm{~min}$ and adequate diffusion and reaction of $\mathrm{MgO}$ in pellet can be fulfilled effectively. Consequently, targeting to obtain enough induration degree and better metallurgical properties, the advisable decisions containing the $\mathrm{MgO}$ content, the proper firing time and firing temperature should be made with comprehensive consideration. The goal is to not only use the positive effect of $\mathrm{MgO}$ on the metallurgical properties, but also to avoid its negative influence on the induration of pellet. Foreseeability, the $\mathrm{MgO}$ flux pellet will be a prospective candidate for ironmaking charging if both the merits and drawbacks of $\mathrm{MgO}$ existing in $\mathrm{MgO}$ flux pellet can be well handled.

\section{Conclusions}

For the purpose of obtaining the induration mechanisms of $\mathrm{MgO}$ flux pellet, both the oxidation process of $\mathrm{Fe}_{3} \mathrm{O}_{4}$ into $\mathrm{Fe}_{2} \mathrm{O}_{3}$ and densification process of pellet were studied. The main findings are summarized as follows:

(1) $\mathrm{MgO}$ is found to adversely affect the oxidation process of $\mathrm{Fe}_{3} \mathrm{O}_{4}$. The oxidation rate of $\mathrm{Fe}_{3} \mathrm{O}_{4}$ for the $\mathrm{MgO}$ bearing reagent ball $\left(w_{(\mathrm{Fe} 3 \mathrm{O} 4)} / w_{(\mathrm{MgO})}=95.0 \% / 5.0 \%\right)$ is slower than that for the base reagent ball $\left(w_{(\mathrm{Fe} 3 \mathrm{O} 4)}=100 \%\right)$.

(2) Based on the unreacted core model, the relationship between the oxidation ratio of $\mathrm{Fe}_{3} \mathrm{O}_{4}(Y)$ and time $(t)$ was proposed. The calculated results coincide well with the experimental data according to the verification experiments. The unreacted core model is therefore suitable to discuss the oxidation of $\mathrm{Fe}_{3} \mathrm{O}_{4}$ in pellet induration process. 
(3) The densification of the pellet is limited after the addition of $\mathrm{MgO}$. The oxide densification index (ODI) of $\mathrm{MgO}$ flux pellet is lower compared with that of Non-MgO flux pellet, which makes CS of the $\mathrm{MgO}$ flux pellet maintain at a lower level.

(4) $\mathrm{MgO}$ negatively affects pellet induration and then restrains the pellet strength. However, prolonging the fired time and adjusting the $\mathrm{MgO}$ dosage are available to overcome these drawbacks. Therefore, the $\mathrm{MgO}$ flux pellet will be a prospective candidate for ironmaking units if an appropriate balance can be made between the merits and drawbacks of $\mathrm{MgO}$ flux pellet.

Author Contributions: Q.G. and X.J. designed the experiments; Q.G. performed the experiments, analyzed the data, and compiled the text; H.Z. and F.S. supervised the experimental work and reviewed the manuscript.

Funding: This research was funded by the National Science Foundation of China $(51604069,51774071$ and 51874080) and the Fundamental Research Funds for the Central Universities, China (N162504004).

Acknowledgments: The authors would like to thank the academic editor and referees for their constructive comments and suggestions which have been used to improve the readability of the paper. Also, the financial support of the National Science Foundation of China (51604069, 51774071 and 51874080) and the Fundamental Research Funds for the Central Universities, China (N162504004) are much appreciated.

Conflicts of Interest: The authors declare no conflict of interest.

\section{References}

1. Nabeel, M.; Karasev, A.; Jönsson, P.G. Evaluation of dust generation during mechanical wear of iron ore pellets. ISIJ Int. 2016, 56, 960-966. [CrossRef]

2. Fu, J.; Zhu, D. Basic Principles, Techniques and Equipment of the Iron Ore Oxidized Pellets; Central South University Press: Changsha, China, 2005; pp. 323-336. ISBN 9787811050516.

3. Nishimura, T.; Higuchi, K.; Naito, M.; Kunitomo, K. Evaluation of softening, shrinking and melting reduction behavior of raw materials for blast furnace. ISIJ Int. 2011, 51, 1316-1321. [CrossRef]

4. Iljana, M.; Kemppainen, A.; Paananen, T.; Mattila, O.; Heikkinen, E.P.; Fabritius, T. Evaluating the reduction-softening behaviour of blast furnace burden with an advanced Test. ISIJ Int. 2016, 56, 1705-1714. [CrossRef]

5. Jiang, X.; Li, X.; Shen, F. Study on improving the softening-melting properties of $\mathrm{MgO}$ bearing iron ores. J. Northeast. Univ. Nat. Sci. 2007, 28, 365-369.

6. Gao, Q.; Shen, F.; Wei, G.; Jiang, X. Gas-solid reduction kinetic model of MgO-fluxed pellets. Int. J. Miner. Metall. Mater. 2014, 21, 12-17. [CrossRef]

7. Kemppainen, A.; Mattila, O.; Heikkinen, E.; Paananen, T.; Fabritius, T. Effect of $\mathrm{H}_{2}-\mathrm{H}_{2} \mathrm{O}$ on the reduction of olivine pellets in CO-CO 2 Gas. ISIJ Int. 2012, 52, 1973-1978. [CrossRef]

8. Matsumura, M.; Hoshi, M.; Kawaguchi, T. Improve of sinter softening property and reducibility by controlling chemical compositions. ISIJ Int. 2005, 45, 598-607. [CrossRef]

9. Shen, F.; Gao, Q.; Wei, G.; Shen, Y. Densification process of MgO bearing pellets. Steel Res. Int. 2015, 86, 644-650. [CrossRef]

10. Ahmed, H.; Semberg, P.; Andersson, C.; Björkman, B. Effect of added olivine on iron ore agglomerate during induration. ISIJ Int. 2018, 58, 446-452. [CrossRef]

11. Li, S.; Chen, T.; Zhang, Y.; Zhao, J. Experimental study on application of Mg-bearing additives in iron ore pellet. Sinter. Pelletizing 2011, 36, 33-37.

12. Semberg, P.; Andersson, C.; Björkman, B. Interaction between iron oxides and olivine in magnetite pellets during reduction to wustite at temperatures of 1000-1300 ${ }^{\circ} \mathrm{C}$. ISIJ Int. 2013, 53, 391-398. [CrossRef]

13. Singh, M.; Björkman, B. Effect of reduction conditions on the swelling behaviour of cement-bonded briquettes. ISIJ Int. 2004, 44, 294-299. [CrossRef]

14. Gao, Q.; Wei, G.; Jiang, X.; Zheng, H.; Shen, F. Characteristics of light-burned magnesia and its application on oxidized pellet production. J. Iron Steel Res. Int. 2014, 21, 408-412. [CrossRef]

15. Chun, T.; Zhu, D.; Pan, J. Influence of sulfur content in raw materials on oxidized pellets. J. Cent. South Univ. Technol. 2011, 18, 1924-1929. [CrossRef]

16. Gao, Q.; Shen, F.; Wei, G.; Jiang, X.; Zheng, H. Effects of MgO containing additive on low-temperature metallurgical properties of oxidized pellet. J. Iron Steel Res. Int. 2013, 20, 25-30. [CrossRef] 
17. Sandeep Kumar, T.; Viswanathan, N.; Ahmed, H.P.; Andersson, C.; Björkman, B. Estimation of sintering kinetics of oxidized magnetite pellet using optical dilatometer. Metall. Mater. Trans. B 2015, 46, $635-643$. [CrossRef]

18. Sandeep Kumar, T.; Viswanathan, N.; Ahmed, H.P.; Andersson, C.; Björkman, B. Estimation of sintering kinetics of oxidized magnetite pellet using optical dilatometer. Metall. Mater. Trans. B 2016, 47, 309-319. [CrossRef]

19. China Metallurgical Construction Association. Code for Design of Iron Pelletizing Engineering; China Planning Press: Beijing, China, 2009; pp. 20-25. ISBN 1580177244.

20. Biswas, A.K. Principles of Blast Furnace Ironmaking; Cootha Publishing House: Brisbane, Australia, 1981; pp. 33-39. ISBN 0949917001.

21. Szekely, J.; Evans, J.; Sohn, H. Gas-Solid Reductions; Academic Press: New York, NY, USA, 1976; pp. $97-102$. ISBN 0126808503.

22. Sohn, H.; Wadsworth, M. Rate Processes of Extractive Metallurgy; Plenum Press: New York, NY, USA, 1979; pp. 115-117. ISBN 030631102X.

23. Eisenhüttenleute, V.D.; Allibert, M. Verlag Stahleisen. In Slag Atlas, 1st ed.; Verlag Stahleisen GmbH: Düsseldorf, Germany, 1995; p. 128. ISBN 3514004579.

24. Bao, Y.; Jin, Z. Size effects and a mean-strength criterion for ceramic. Fatingue Fract. Eng. Mater. Struct. 1998, 8, 55-61. [CrossRef]

25. Gibson, L.; Ashby, M. Cellular Solids: Structure and Propertie; Cambridge University Press: Cambridge, UK, 1997; pp. 150-158. ISBN 9780521499118.

26. Suresh, S. Fatigue of Materials; Cambridge University Press: Cambridge, UK, 1998; pp. 70-75. ISBN 9780521578479.

27. Iljana, M.; Mattila, O.; Alatarvas, T.; Kurikkala, J.; Paananen, T.; Fabritius, T. Effect of circulating elements on the dynamic reduction swelling behaviour of olivine and acid iron ore pellets under simulated blast furnace shaft conditions. ISIJ Int. 2013, 53, 419-426. [CrossRef]

28. Shen, F.; Gao, Q.; Jiang, X.; Wei, G.; Zheng, H. Effect of magnesia on the compressive strength of pellets. Int. J. Miner. Metall. Mater. 2014, 21, 431-437. [CrossRef]

29. Gao, Q.; Shen, Y.; Wei, G.; Jiang, X.; Shen, F. Diffusion behavior and distribution regulation of $\mathrm{MgO}$ in MgO-bearing pellets. Int. J. Miner. Metall. Mater. 2016, 23, 1011-1018. [CrossRef] 